\title{
FUNCIONAMIENTO DEL CONCEJO MURCIANO (1462-1474)
}

Por

M.a BELEN PIQUERAS GARCIA 
Julio Valdeón Baruque en su estudio sobre «Una ciudad castellana en la segunda mitad del siglo XIV» dice: «El concejo es un organismo político que extiende su esfera de actuación sobre todos los vecinos del término que engloban (1).

Los concejos castellanos bajomedievales constan de dos elementos integrantes básicos:

La asamblea y los oficiales, encargados de procurar resolver los distintos problemas que se plantean a los habitantes de la ciudad en su vida colectiva, problemas de diversa índole entre los que podemos destacar, a tenor de los datos obtenidos en los libros de Actas Capitulares de estos años, el mantenimiento del orden, aplicación de las leyes vigentes, procurar el normal abastecimiento alimenticio de la ciudad, control de precios, salarios, etc.

Las autoridades concejiles no cesaron en su empeño de garantizar la seguridad ciudadana, base imprescindible para la posible convivencia entre los vecinos de Murcia y para su participación en el desarrollo de la vida ciudadana. En este orden quedaba prohibido a los habitanes de la ciudad del Segura salir de sus casas, una vez que hubiese

(1) Valdeón Baruque, Julio: «Una ciudad castella en la segunda mitad del siglo XIV: el ejemplo de Murcian, Anexos de Hispania, III, C.S.I.C., Madrid, 1969. 
sido tañida la campana del alguacil, agravándose la culpa en el caso de que fuesen armados. Unicamente estaba pemitido a aquellas personas que tuviesen que resolver asuntos de tal importancia que no admitiesen dilación, siendo condición imprescindible el que portasen lámparas encendidas para hacerse visibles (2).

En el mes de noviembre de 1464 dispusieron unas ordenanzas encaminadas a conseguir que en la ciudad hubiese justicia y orden, siendo castigados todos aquellos que contraviniesen lo acordado:

* La campana del alguacil debía tañerse desde el día de San Miguel de Septiembre hasta finales de Marzo, a las ocho de la tarde y desde el primer día de Abril hasta San Miguel a las nueve. Esta campana se tañía durante media hora para que los vecinos, al oírla, tuviesen tiempo de recogerse en sus respectivas casas.

* Nadie debía llevar armas, excepto espadas y puñales durante el día, bajo ningún concepto durante la noche una vez que hubiese sido tañida dicha campana, excluyendo de esta orden a la justicia.

* Para que la ciudad estuviese mejor vigilada durante la noche, impidiendo que se produjesen robos, acordaron que el Alguacil Mayor designase en cada colación a un alguacil menor, con autoridad suficiente para proceder contra quienes vagasen de noche, con intenciones de hurto.

* Quienes organizasen peleas serían desterrados de la ciudad por un año, tras haberles despojado de su ropa y armas.

* Quedaba prohibido andar de noche tanto por Murcia como por sus arrabales, organizando ruido y alboroto, salvo en caso de bodas, penando a los infractores con permanecer durante seis días en la cadena.

(2) A.M.M., Ac. Cap. 1463-64, sesión: Sábado, 7-1-64. La pena impuesta a los que infringian la orden era de $100 \mathrm{mrs}$. 
Los señores Adelantado, concejo, justicia, regidores, Don Pedro Vélez de Guevara y algunos otros hombres honrados de la ciudad juraron guardar y cumplir dichas ordenanzas, no intercediendo por aquellas personas que las quebrantasen (3).

Estas ordenanzas concejiles no debieron acatarse, de manera satisfactoria para las autoridades, en el barrio de la putería ni en su arrables, haciéndose necesario que fueran nuevamente reiteradas en 1468, prohibiendo expresamente llevar puñales, espadas y otras armas bajo pena de perderlas y pagar la pena que el concejo estipulase (4).

No obstante y sin mermar la importancia de otros asuntos los problemas económicos son, sin lugar a dudas, los que ocupan el primer puesto en las atenciones del concejo murciano.

Durante la época objeto de este estudio, el gobierno del concejo de Murcia estuvo confiado a un cuerpo de funcionarios -asamblea y oficiales-, que formaban el ayuntamiento. Abellán Pérez expone: «Durante el siglo XV la administración local se ejerce en la ciudad de Murcia a través de su organismo rector el concejo, con plena autonomía en sus funciones, aunque sometido a una soberanía exterior, la del Rey" (5).

En el seno de este concejo se advierte una clara jerarquización de funciones y de cometidos.

Al frente de la administración del municipio, en el lugar más destacado, se hallaba el corregidor, representante directo de la Corona y dotado de una amplia gama de poderes, tanto judiciales como ejecutivos. Como funcionario regio presidía los «ayuntamientos» adoptando

(3) A.M.M., Ac. Cap. 1464-65, sesión: Sábado, 17-XI-64, fol. 57r.

(4) A.M.M, Ac. Cap. 1468-69, sesión: Sábado, 13-VIII-68.

(5) Abellán Pérez, Juan: «El concejo murciano de junio de 1429 a junio de 1430: Su estructura», Miscelánea Medieval Murciana, V, 1980, pág. 121-158. 
decisiones y haciendo cumplir las órdenes reales, a la vez que informaba al monarca y fiscalizaba la política interna del municipio.

En ausencia del corregidor o asistente era el señor Adelantado quien presidía los ayuntamientos.

Los restantes miembros que configuraban el concejo eran vecinos de Murcia, designados para desempeñar cargos y funciones específicamente concejiles: Alcaldes mayores, Alguacil mayor (6), regidores y jurados, representantes estos últimos de los pecheros de las distintas colaciones que habra en Murcia.

El concejo se reunía de forma fija los Martes y Sábados de cada semana y de forma esporádica algunos otros días. El lugar normal de estas reuniones era "La Cámara de la sala de la Corte». Aunque en ocasiones los ayuntamientos eran celebrados en el porche e Iglesia de Santa Catalina, en el cementerio, en la casa donde vivía Fernando Martínez de Alcaraz, ubicada en el mercado de la ciudad y en la Iglesia de Santa María la Mayor, este último lugar solía ser el marco elegido para la inauguración del nuevo año concejil, con la elección de los nuevos cargos y su posterior juramento (7).

Los Martes y Sábados coincidentes con alguna festividad religiosa no tenían lugar las sesiones del concejo, asimismo la muerte de algu-

(6) El nombramiento de un corregidor llevaba paralelo el cese de estas figuras, dado que en Murcia fue designado un Asistente, Pedro de Castro y, posteriormente Alfonso López de la Cuadra, intitulado indistintamente como corregidor y Asistente, anualmente fueron designados los dos Alcaldes y el Alguacil.

(7) A.M.M. Ac. Cap. 1462-63, sesión: Jueves, 15-VII-62, se reunieron en la plaza del mercado de la ciudad.

A.M., Ac. Cap. 1462-63, sesión: Lunes, 16-VIII-62 y Domingo, 18-XII-63, se reúnen en el porche de Santa Catalina.

En Domingo, 30-XII-65 leemos: «Reunidos en la Iglesia de Santa Catalina».

E1 Jueves, 12-I-69 se reunieron en las casás donde vivía Fernando Martínez de Alcaraz, en el mercado. 
nos de sus miembros o de familiares directos de éstos, mujer e hijos, eximía de su celebración (8).

En ocasiones queda reflejada en los libros de actas de estos años, la hora en la que tenía lugar la reunión concejil (9).

En la sala de la corte, lugar donde por regla general eran celebrados los cabildos, había una pintura con la imagen del Señor, con un altar a sus pies para cuando fuese necesario celebrar Misa (10).

Según acuerdo concejil de 1462 las reuniones del concejo se abrían tras rezar una oración (11), debiendo asistir a estas asambleas todos sus miembros. La no asistencia de algunos componentes del $\mathrm{Ca}$ bildo debió ser frecuente e incluso en algunas ocasiones abusivas, obligando a que se tomasen medidas para zanjar el problema. En 1470 acordaron imponer un real de multa por cada vez que los regidores y jurados se ausentasen del concejo sin tener licencia para ello (12). No se permitía tampoco salirse de un ayuntamiento sin licencia de los presentes en el mismo (13).

El escribano del concejo levantaba acta de todo lo tratado en las sesiones, siendo trasladado luego a los libros de actas capitulares.

(8) A.M.M., Ac. Cap. 1462-63, sesión: Sábado, 18-XII-62. No hubo concejo por ser la festividad de Santa María de la $O$.

A.M.M. Ac. Cap. 1463-64, sesión: Martes, 10-IV-64, no hubo concejo por ser el entierro de Pedro Escarramad, regidor.

A.M.M. Ac. Cap. 1462-63, sesión: Martes, 6-VII-62, no hubo concejo por la muerte de la mujer de Juan Alfonso de Cascales, regidor.

(9) A.M.M., Ac. Cap. 1464-65, sesión: Sáabado, 24-VI-64: «Ayuntados a conçejo a la hora de visperas...)

(10) A.M.M. Ac. Cap. 1462-63, sesión: Martes, 14-XII-62.

(11) Id. nota anterior.

(12) A.M.M. Ac. Cap. 1470-71, sesión: Martes, 16-X-70.

(13) A.M.M. Ac. Cap. 1473-74, sesión: Sábado, 20-XI-73. En esta sesión concejil los regidores juraron guardar el acuerdo de no ausentarse una vez empezados los ayuntamientos, sin licencia de los presentes. 
Estos libros de actas reflejan cómo con el paso de los años se fue perfilando el funcionamiento interno de las reuniones concejiles, muestra de ello es la decisión adoptada en 1469 , con el propósito de despachar con mayor rapidez los asuntos del concejo acordaron que en cada una de las sesiones celebradas, el escribano debía nombrar un presidente moderador regidor o jurado, para dirigir el turno de las intervenciones (14). Cualquier regidor o jurado que interrumpiera a quien estuviese hablando en el ayuntamiento, con la licencia del presidente, estaba obligado a pagar 20 maravedís de multa por cada vez que incurriese en dicha falta. El dinero se destinaba a comprar fruta y vino para el resto de los oficiales que estuviesen aquel día presentes en el ayuntamiento (15).

Para conseguir un mayor orden durante la celebración de las reuniones e instar a sus miembros a guardar compostura, en 1472 se prohibió a todos los oficiales, alcaldes, regidores, alguacil y jurados sentarse en las ventanas que había en la sala de la corte, en lugar de ocupar los asientos. Para impedir que la costumbre continuase ordenaron al mayordomo que diese orden de poner barras de madera, at ravesadas en las ventanas, para hacer que fuese imposible sentarse en las mismas (16).

El día 24 de junio, festividad de San Juan Bautista, era la fecha fijada para el comienzo de un nuevo año concejil, siendo el momento en que debían renovarse la mayoría de los cargos concejiles de duración anual, a excepción de los alcaldes de la huerta y sobrecequieros de las acequias mayores de Alquibla y Aljufía, cuya elección tenía lugar durante la Pascua, hasta que en 1469 el concejo resolvió que dicha elección y nombramiento de estos oficiales debía efectuarse ocho días antes de la Pascua y la elección de los alcaldes ordinarios, alguacil, almotacén, mayordomo y alcalde de los pleitos que surgiesen

(14) A.M.M. Ac. Cap. 1468-69, sesión: Sábado, 10-VI-69.

(15) A.M.M. Ac. Cap. 1469-70, sesión: Martes, 27-VI-69.

(16) A.M. Ac. Cap. 1471-72, sesión: Sábado, 23-V-72. 
entre judíos y cristianos, tendría lugar el día de San Bernabé, siendo la cámara del ayuntamiento el lugar designado para efectuar dichos nombramientos. Condición imprescindible para poder ser elegidos era el que desde un año antes de ello estuviesen manteniendo caballo y armas, habiendo hecho los alardes ante los alcaldes de la ciudad.

Los candidatos tenían la obligación de inscribirse ante el escribano del concejo, quien no los daba a conocer hasta el mismo día de la elección (17).

Fue en 1469 igualmente cuando por acuerdo tomado en el ayuntamiento, encaminado a garantizar el recto funcionamiento interno del concejo, ordenaron que cualquier regidor, jurado u otro oficial que desvelase los secretos oficiales, revelándolos a personas ajenas al cabildo sería excluido de la cámara del ayuntamiento, no pudiendo volver a entrar en la misma durante un año, penalizándolos con la pérdida de su salario y la imposibilidad de gozar durante ese tiempo de ningún ot ro oficio (18).

En 1467 el señor Adelantado Don Pedro Fajardo junto con Don Pedro Vélez, comendador de Ricote, hicieron juramento de no demandar ni procurar en adelante, por sí ni por otras personas, ninguno de los oficios que el concejo acostumbraba dar los días de San Juan de Junio y Pascua Florida, dejando su elección y determinación a los regidores, jurados y justicias de la ciudad, bajo pena de perjuros (19). Este acuerdo denuncia la no demasiada transparencia con que eǹ ocasiones se efectuaban los nombramientos de oficiales del concejo. Ahora bien, con ello no se marcó el punto final de las irregularidades existentes, sino que únicamente supuso una pequeña luz roja que no tardaría en volver a dar paso a las situaciones que provocaron la denuncia.

(17) A.M.M. Ac. Cap. 1468-69, sesión: Sábado, 10-VI-69.

(18) A.M.M. Ac. Cap. 1468-69, sesión: Sábado, 3-VI-69.

(19) A.M.M. Ac. Cap. 1466-67, sesión: Sábado, 16-V-67. 
Tras la elección, los nuevos oficiales del concejo prestaban juramento del buen desempeño de sus cargos, prometiendo guardarlos y cumplirlos «fiel y lealmente, para bien de la çibdad, de sus veçinos y moradores». El lugar de proclamación y juramento solía ser la Iglesia de Santa María la Mayor. Tras ello, y en una nueva sesión concejil, los nuevos oficiales estaban obligados a presentar fiadores que los avalasen, siempre en presencia de testigos (20).

El juramento comportaba a su vez un compromiso a una serie de capítulos aprobados en «ayuntamiento». Para que sirva de ejemplo pasamos a exponer los capítulos jurados por los oficiales para el año concejil 1463-1464:

* Debían guardar siempre y en todo el servicio del Rey ayudando a sus recaudadores y no contraviniéndoles en ninguna ocasión.

* Juraron guardar, cumplir, así como hacer guardar y hacer cumplir los fueros, privilegios, gracias, mercedes y libertades de la ciudad, abogando siempre por la verdad.

* Juraron defender a todas las personas, sin tener en cuenta su condición o estado.

\section{Alcaldes}

* Los alcaldes atenderían a todas aquellas personas que les pidiesen licencia no llevándoles diezmo por ello, únicamente siete maravedís por la petición y otros siete por la confirmación.

* No llevarían diezmo cuando tuviesen que hacer o mandar hacer ejecuciones en bienes de alguna o algunas personas a causa de sus deudas.

(20) A.M.M. Ac. Cap. 1462-63, sesión: Jueves, 24-VI-62. 
* Los alcaldes no debían permitir que los escribanos tomasen prendas por los derechos escritos.

* Cuando fuese anunciada alguna pelea, los alcaldes no tomarían las armas que pudiesen llevar los autores de la disputa, sino que los entregarían al alguacil para que él ejecutase justicia.

* Se comprometieron los mismos a no recibir en los pleitos que ante ellos estuviesen pendientes, escritos, que no fuesen firmados por un letrado graduado.

Asimismo no debían permitir que los abogados fuesen y actuasen como procuradores, ni viceversa, sino que cada uno desempeñase su oficio según estaba ordenado. En caso contrario los alcaldes ejecutarían en ellos las penas dispuestas por el concejo para tales casos.

* Juraron desempeñar sus cargos personalmente, permaneciendo en la ciudad y no pudiendo delegar en otras personas, salvo en aquellos casos establecidos y contemplados por la ley del fuero.

En caso de tener que tomar delegados, estos no podrían ser los mismos del año anterior, ni tampoco debían ser regidores, jurados u oficiales del concejo.

* Juraron no llevar ni consentir llevar a sus asesores ni lugartenientes, dinero alguno por los pleitos que ante ellos se tratasen, excepto una blanca por el registro del proceso.

* Asimismo juraron no llevar ningún dinero por los mandamientos ni por apresar o soltar alguna persona, únicamente el escribano cobraría un maravedí.

* Tampoco demandarían nada por las cartas que librasen o firmasen, salvo un maravedí por el sello. 
* Quedaba prohibido que desempeñasen el oficio varios alcaldes conjuntamente.

* Juraron los alcaldes y el alguacil, cumplir y solucionar las querellas que pudiesen surgir contra ellos durante el tiempo del desempeño de su cargo, respondiendo a dichas querellas de palabra.

* Juraron el alguacil y el almotacén que únicamente designarían como lugartenientes en sus oficios, a personas que fuesen vecinos de la ciudad, no pudiendo acceder a este cargo quienes ya lo hubiesen sido el año anterior, no consintiendo en ello ni aunque les fuese rogado por el concejo, bajo pena de perjuros.

* Les impedían cobrar de carcelaje más de ocho maravedís de tres blancas por los hijosdalgos, judíos y moros, además de un maravedí de entrada y otro de salida.

\section{Alguacil}

* Juró el alguacil no consentir ni a su lugarteniente ni a sus peones, que llevasen, por las prendas que hiciesen, más de un maravedí por cada una de ellas.

* El alguacil no debía tener ni mantener relación alguna con los entregadores que los alcaldes ordinarios, alcalde de los judíos, ejecutores, almotacén y alcaldes de la huerta pusiesen para ejecutar los derechos que a cada uno de ellos les pertenecía por sus oficios.

* Juró el alguacil que de la mejor manera posible y no anteponiendo sus intereses personales, ejecutaría y haría ejecutar, cuando así le fuese mandado, todas las sentencias del concejo, del asistente, alcaldes ordinarios y de todos los demás alcaldes y jueces de la ciu- 
dad. Ejecutando, igualmente, todo lo referente a asuntos de la ciudad y de su huerta.

* Juró no sacar de la prisión a ninguna persona, sin previa orden del juez que hubiese emitido la sentencia. Comprometiéndose a que su lugarteniente también lo guardase.

* Se comprometió a llevar él personalmente el pendón de la ciudad, en todas las ocasiones que fuese sacado, no encomendándolo a su lugarteniente sin tener previo permiso para ello de los regidores de la ciudad.

* Juraron los alcaldes que de las prendas que hiciesen de las personas que debían tener y mantener caballo y armas no llevarian por su derecho más de seis blancas y otras seis para el escribano ante quien se hiciesen dichas prendas. Comprometiéndose a devolver las prendas tomadas a quienes no estuviesen obligados a tener y mantener caballo y armas.

* Los alcaldes, alguacil, almotacén y mayordomo tenían derecho a poseer caballo y armas, debiendo estar al servicio del Rey y del concejo.

* Juraron acatar y cumplir todos estos compromisos ya que de lo contrario serían penados.

Tras estos juramentos manifestaron su compromiso y respondiendo a los juramentos dijeron: "Juramos y prometemos, Amén.» (21).

Por último y antes de pasar a analizar la figura de cada uno de los miembros integrantes del concejo, cabe apuntar cómo algunos de

(21) A.M.M. Ac. Cap. 1463-64, sesión: V iernes, 24-VI-63. 
ellos en razón de su oficio debían pagar una cantidad fija de dinero anualmente, en concepto de fianza, trescientos setenta y cinco maravedís. Esto se mantuvo a lo largo de todo el período que nos ocupa (22).

\section{I.- CARGOS CONCEJILES}

1. Corregidores y Asistentes. Enfrentamiento Asistente - Adelantado.

Estos cargos eran de nombramiento real. La esporádica presencia de delegados enviados por el Rey al concejo para la resolución de problemas muy diversos, fue consante desde la época de Alfonso X.

Los corregidores se convirtieron en asiduos representantes del Rey en el concejo.

Las primeras referencias sobre «jueces corregidores» de los pleitos de la justicia datan de las Cortes de Alcalá de Henares de 1348, aunque no se generalizan hasta el reinado de Enrique III, a partir de entonces adquirieron sus característicos rasgos institucionales.

González A lonso en su estdio sobre «El Corregidor Castellano» expone: "... el corregidor es para las ciudades un oficial excepcional, del cual se puede y se debe hacer uso cuando las tensiones municipales suban de punto y amenacen la paz pública, sólo entonces» (23).

El nombramiento de los corregidores y asistentes correspondía realizarlo al Rey, quien por propia iniciativa, utilizando cualquier ocasión o pretexto procedía a su envío.

(22) En 1475, apenas comenzado el reinado de los Reyes Católicos, encontramos en una sesión del concejo, la orden expresa de que en lo sucesivo los alcaldes, alguacil y almotacén, debían pagar cada año $375 \mathrm{mrs}$. al concejo, por razón de sus oficios.

A.M.M. Ac. Cap. 1474-75, sesión: Sábado, 20-V-75.

(23) Gonzílez Alonso, B: "El corregidor castellano (1348-1808)", Estudios de Historia de la Administración. Instituto de Estudios Administrativos, Madrid, 1970. 
La diferencia existente entre corregidor y asistente es mínima, en realidad gozaban de las mismas atribuciones, diferenciándose únicamente en que el nombramiento y envio de asistente a una ciudad, no comportaba la supresión de los alcaldes y alguacil concejiles, como ocurría en caso de ser enviados corregidores, resultando de esta manera una menor presión del poder real sobre la ciudad.

En la práctica la presencia de estos delegados era una amenaza constante y directa para la autonomía administrativa de los concejos, así como una pesada carga económica para los vecinos pecheros. Su llegada originaba un gran descontento en los municipios.

Los requisitos personales a reunir por estos oficiales eran los normalmente requeridos a los jueces: buena fama, lealtad, nivel adecuado para juzgar en los pleitos, carácter pacífico, espíritu religioso.

Durante el período 1464-1474 la documentación registra la presencia en Murcia de dos asistentes, Pedro de Castro (1460-1465) y Alfonso López de la Cuadra (1466-1468), éste último aparece intitulado indistintamente como corregidor y asistente en la documentación de estos años. Así lo encontramos nombrado por vez primera como corregidor en la sesión del concejo del sábado 19 de diciembre de 1467 y como corregidor y asistente juntamente en sábado 11 de marzo de 1469.

Tras el nombramiento del corregidor o asistente, concretado en una carta real (24), le seguía la toma de posesión realizada en el pro-

(24) En 1460 fueron enviadas diversas cartas al concejo de la ciudad de Murcia, anunciando la llegada del asistente Pedro de Castro.

A.M.M. Cart. Real 1453-1478, fol. 108v, Segovia, 8-X-146(). Al concejo de Murcia para que recibieran como Asistene a Pedro de Castro.

Cart. Real 1453-1478, fol. 108v, Segovia, 8-X-1460. Al concejo de Murcia, sobre el nombramiento de Pedro de Castro como Asistente Real.

Cart. 1453-1478, fol. 109r., Medina del Campo, 10-XJ-1460. Al concejo de Murcia, para que obedeciesen a Pedro de Castro. 
pio con cejo al que era enviado, en ella se le investía con los aributos propios del cargo, entregándole la vara de la justicia.

«...Por ende yo vos ruego e mando syn escusa alguna lo reçibades al dicho ofiçio de asistençia e le dexedes e consyntades libremente usar del, e que vos confermedes todos con el para guardar lo que a mi serviçio e exsecuçión de la dicha mi justiçia e al bien desta dicha mi çibdad cunple, en lo qual mucho plazer e serviçio me fareys...» (25).

Estos delegados gozaban de diversas competencias y facultades de gran importancia, abarcando desde el ámbito judicial y administrativo - presidía los concejos y participaba en ellos con voz y voto- (26), hasta tareas encauzadas al mantenimiento del orden público.

En 1464 tras prorrogar en su cargo de asistente durante un año más a Pedro de Castro, Enrique IV mandó una carta a Murcia instando a que le recibiesen por asistente debiendo estar presente Pedro de Castro en todos los ayuntamientos, el concejo no podría reunirse sin contar con su presencia, debiendo acatar y cumplir lo que dispusiese como si fuera mandato directo del Rey, ya que tenía facultad para hacer salir de la ciudad a todas las personas que fuesen remisas en el cumplimiento de sus órdenes (27).

La duración de su cargo no se ajustaba a la anualidad pensada en el momento de su nombramiento.

Según los datos conservados el sueldo percibido por estos dos delegados regios con los que contó Murcia durante 1460-1468, fue de 20.000 maravedís anuales (28).

(25) A.M.M., Cart. Real 1453-1478, fol. 108v, Segovia, 8-X-1460.

(26) A.M.M., Ac. Cap. 1462-63, sesión: Miércoles, 23-V1-62. Estaba presente en todas las reuniones concejiles y aprobaba la elección de los oficios, en presencia de testigos.

(27) A.M.M., Ac. Cap. 1464-65, sesión: Sábado, 24-VI-64.

(28) A.M.M., Ac. Cap. 1462-63, sesión: Sábado, 26-VI-62: Ordenan al Mayordomo Pe- 
Según leemos en el estudio de Torres Fontes sobre la "Crónica de Enrique IV»: «la ciudad de Murcia se quejaba al Rey de las atribuciones que el asistente Pedro de Castro usaba, por virtud de las cuales podía desterrar de la ciudad a quienes entendra no poder permanecer dentro de ella y podía ejecutar la justicia en caso de negligencia. Ante esta protesta el Rey confirmó las atribuciones del asistente "porque es su real justicia la que éste cumple", (a lo que apunta dicho autor) que dicha carta prueba el decaimiento de la autonomía municipal y la tendencia centralizadora de los monarcas, que merma los derechos ciudadanos; proceso que culmina, más tarde, bajo el cetro de los Reyes Católicos (29). No obstante no tardó mucho en cambiar por completo la situación, debiéndose hablar de una total decadencia del poder real que llevó a que la labor de estos letrados reales acabase por ser totalmente inútil.

A partir de la deposición de Enrique IV en Avila y de las repercusiones de la guerra civil castellana, el concejo y la ciudad de Murcia cayeron bajo el control directo de Don Pedro Fajardo, Adelantado Mayor, quien llegó a ser la verdadera autoridad que controló el destino de Murcia durante estos años.

El asistente Don Pedro de Castro en un principio llegó a oscurecer la figura del Adelantado, en este orden, el delegado real intentó, como medio para una mayor directa intervención en el municipio, que los regimientos fuesen anuales. Ante ello los regidores elevaron su protesta y como resultado, en las Cortes de Toledo de 1462, se acordó que ni los corregidores ni asistentes pudiesen ser prorrogados

dro González que pagase 2.000 maravedís al Señor Asistente «para ayuda de su mantenimiento", según lo habra ordenado el Rey, efectuando el pago en tercios.

Ac. Cap. 1463-64, sesión: Martes, 9-VIII-63: Ordenan al mayordomo que pagase a Pedro de Castro, guarda y vasallo del Rey y su Asistente, 2.000 maravedís de dos blancas, cada año.

Ac. Cap. 1464-65, sesiones: Sábado, 24-VI-64, y Sábado, 7-VII-64.

(29) Torres Fontes, Junn: Estudio sobre la "Crónica de Enrique Cuarto", del Dr. Galindez de Carvajal, Murcia 1940, pág. 501. 
en sus oficios de justicia por más de un año, no obstante y como muestran los hechos, estos cargos siguieron prorrogándose por más de un año.

Pedro de Castro, tras el acuerdo tomado en las Cortes, pasaba a ser únicamente alcaide de Alcázar.

En el libro del Acta Capitular de 1464 queda registrada la decisión de que en lo sucesivo el citado asistente no debía seguir ostentando su cargo, alegando para ello el que en las Cortes que el Rey celebró en Toledo, en 1462 (30), se asentó que ningún alcaide en el lu gar que tuviese fortaleza o castillo, en cinco leguas a la redonda, pudiese ejercer el oficio de corregidor, pesquisidor, asistente, alcalde de sacas, alguacil ni cualquier otro oficio de juzgado. Asimismo se acordó que no podrían ejercer su cargo por más de un año, excepto en caso demostrable de un buen desempeño del oficio, en que se podía prorrogar por otro año, pero no más (31).

Así pues Pedro de Castro quedaba reconocido únicamente como alcaide del Alcázar, aún así el señor Adelantado seguía viendo en él una amenaza. Para evitarla se llegó a la firma de una Hermandad general de las ciudades de Murcia, Lorca y Cartagena con Don Pedro Fajardo, aprobándose unos capítulos por los cuales el Adelantado juró defender la Hermandad y las ciudades prometieron su obediencia y ayuda. De esta forma Don Pedro Fajardo restablecía su poderío en el reino murciano.

Aprovechándose de la decadencia del poder real le fue fácil atraerse a las ciudades murcianas, proponiéndose cercar el Alcázar para aca-

(30) Cortes de los Antiguos reinos de León y Castilla, publicada por la Real Academia de la Historia, Madrid, 1866, III pág. 704-705.

(31) A.M.M., Ac. Cap. 1464-65, sesión: Sábado, 22-IX-64. 
bar con el asistente, último jalón representativo del menguado poder real en Murcia (32).

Don Pedro Fajardo logró poner de acuerdo a los regidores para que cercasen el Alcázar. En las Actas abundan las noticias, datos y detalles de los preparativos y gastos hechos en el cerco de la fortaleza, para el que se necesitó un mes y medio, hasta que por fin se logró la capitulación, entregando Pedro de Castro el Alcázar (33).

Tras ello se acordó que el que antes fuese asistente podría residir con sus familiares y servidores en Murcia o en cualquier otro lugar del Reino, siéndole devueltas todas las prendas tomadas, así como salarios at rasados.

Cerdá Ruiz Funes en su estudio sobre los Adelantados los define como oficiales nombrados por el Rey o al menos confirmdos sus nombramientos por el monarca, que dentro del territorio de su adelantamiento tendrá las mismas facultades que el monarca en su reino con la única excepción de las limitaciones que el propio Rey nominalmente le señale, gozando de atribuciones judiciales y de tipo militar así como facultades para intervenir directamente en las cuestiones económicas (34).

Torres Fontes, en el estudio de la biografía de Don Pedro Fajardo, apunta cómo en el período 1465-1475 llegó a ejercer un poder omnímodo, conociendo e interviniendo en todos los asuntos del Adelantamiento y de sus ciudades.

(32) Torres Fontes, Junn: Don Pedro Fajardo. Adelantado Mayor del Reino de Murcia. C.S.I.C., Patronato "Marcelino Menéndez Pelayon, Biblioteca Reyes Católicos, Madrid, 1958.

(33) A.M., Ac. Cap. 1464-65, sesión: 20-XI-64.

(34) Cerdá Ruiz-Funez, J: "Adelantados Mayores y concejo de Murcia (notas para un estudio histórico-jurídico)», en Primera semana de estudios Murcianos, I, Murcia, 1961. 
De hecho se había convertido en un virrey, pues las numerosas atribuciones que poseía las ejercía no propiamente como Adelantado Mayor, sino por los otros cargos que desempeñaba (35).

Cerdá recoge una frase encontrada en las Actas del concejo: «...en presencia del Señor Adelantado a quien tiene la ciudad casi por un virrey" (36).

Una muestra de este poder es el hecho ocurrido en 1469 -hecho que no tiene antecedentes-, Don Pedro Fajardo se hizo eregir regidor del municipio de Murcia, para así poder intervenir, con los mismos derechos y obligaciones que los otros regidores, en las deliberaciones del concejo o regimiento.

En la sesión concejil del mes de Junio de 1469 queda recogida esta circunstancia, Antón Martínez, regidor, expuso ante los demás regidores cómo la ciudad estaba alterada por el hecho de no guardar obediencia a ningún Rey, tras el fallecimiento de don Alfonso, por lo que, para evitar inconvenientes, los regidores decidieron nombrar como nuevo regidor de la ciudad al Adelantado Don Pedro de Castro, que ocuparía el lugar que le cedía Diego Riquelme (37).

En tanto la guerra civil asolaba a Castilla, los juristas y letrados que constituían el consejo real de Don Alfonso, siguiendo las normas trazadas en los reinados anteriores y de las ideas jurídicas que estaban en vigor, se preocupaban del gobierno y regimiento de las ciudades, y así a finales de 1466 fue nombrado corregidor de Murcia el licenciado en Decretos Alfonso López de la Cuadra (38). El se propuso acabar

(35) Torres Fontes, J: Don Pedro Fajardo, Adelantado Mayor del Reino de Murcia, CSI.C., Ob. cit. págs. 119 y 129.

(36) Cerdí Ruiz-Funes, J: Ob. cit. pág. 11.

(37) A.M.M., Ac. Cap. 1468-69, sesión: Sábado, 3-VI-69.

(38) En los libros de Actas, como ya hemos apuntado anteriormente, aparece indistintamente como corregidor y asistente. 
con la anarquía reinante en el municipio y las excesivas libertades que se habían arrogado los regidores (39).

En Murcia el concejo lo recibió como asistente en el mes de Diciembre. Don Alfonso compareció ante Francisco Pérez Beltrán, escribano del concejo, y presentó una carta del Rey, por la que pedía le recibiesen por asistente.

El concejo esperó al siguiente día para dar su respuesta, acatando la orden real. En dicha respuesta del ayuntamiento se apuntan como obligaciones del asistente: "guardar y hazer guarzar los fueros, previlegios y franquizias y libertades de la çibdad» (40).

En 1468, tras la muerte de Don Alfonso y a instancias del Adelantado, quien estaba cansado de la dirección del nuevo corregidor, se alegó que con la muerte del Rey expiraba el corregimiento de Licenciado, por lo que el concejo pedía resolución para este asunto, acordando que no siguiese desempeñando el cargo (41).

Comenzaba en estos momentos el gobierno independiente del Adelantado Don Pedro Fajardo, sus atribuciones no cesaron con la subida al trono de los Reyes Católicos, quienes le siguieron reconociendo como Adelantado, ello queda reflejado en la carta de los señores reyes que Don Pedro Fajardo presentó e hizo leer ante el ayuntamiento, reunido en la Iglesia de Santa María La Mayor, el Domingo 16 de Abril de 1475, en presencia del escribano Francisco Pérez Beltrán. Por esta carta Sus Altezas le daban poder para entender en la defensa del Reino de Murcia, así contra moros como contra otras personas, instando a que le prestasen ayuda para ello (42).

(39) Torres Fontes, J: Ob. Cit., págs. 103.

(40) A.M.M, Ac. Cap. 1466-67, sesiones: Martes, 30-XII-66 y Miércoles, 31-XII-66.

(41) A.M.M, Ac. Cap. 1468-69, sesión: Miércoles, 27-VII-68, y en Sábado, 30-V-68. A la hora de vísperas, el escribano del concejo levantó acta de cómo el licenciado Alfonso López de la Cuadra, conformándose con la decisión del Ayuntamiento depositó su vara de Corregidor y la de justicia.

(42) A.M.M., Ac. Cap. 1474-75, sesión: Domingo, 16-IV-75. 


\section{Regidores}

Fue también éste un cargo de nombramiento real. Alfonso XI fue el primero que nombró regidores en los municipios castellanos, como es el caso de Murcia, en donde en 1326, designó cuarenta de estos oficiales (43).

Fue durante el reinado de Enrique II cuando comenzó a generalizarse el uso del término regidor.

En cuanto a su elección se hacía conforme había quedado establecido a partir de Juan II en 1424 (44). Producida una vacante el concejo proponía una terna de candidatos al monarca, quien elegía a uno de ellos por regidor de la ciudad, tras lo cual prestaban juramento ante el delegado real (Adelantado o corregidor). El juramento se hacía en nombre de Dios y con los "Santos Evangelios» en la mano, jurando desempeñarlo bien y lealmente, era la fórmula habitual.

No obstante durante el reinado de Enrique IV fue usual el nombramiento de regidores no incluidos en la lista propuesta por el concejo, asimismo tampoco se respetaría el número de dieciséis regidurías establecidas por Juan II sino que éstas experimentaron un gran crecimiento, llegando a significar un problema necesario de resolver. Ante él la política de Enrique IV fue muy vacilante, en un momento dado revocó gran número de ellas, así ocurrió en 1469, tras la petición de los procuradores de las ciudades y villas (45), más tarde y de forma contradictoria fueron nuevamente nombrados gran número de regidores. Así en 1472 leemos en el Acta Capitular cómo, dado que

(43) Torres Fontes, J: "El concejo murciano en el reinado de Alfonso XI", en A.H.D.E., XXIV, Madrid, 1953, págs. 5-25.

(44) La normativa se hizo saber por dos cartas enviadas a Murcia con fecha: Toledo, 14-III-1424, presentadas por Aabellán PÉrez, J: El concejo murciano... ob. cit. Incluidas posteriormente en la Colección de Documentos para la Historia del Reino de Murcia, XVI. Documentos de Juan II, ed, de Abellán Pérez, Murcia-Cádiz, 1984.

(45) Cortes de León y Castilla, III, pág. 786. 
había un número mayor de regidores del que debía haber, juraron en el ayuntamiento no recibir nuevos regidores ni cubrir las vacantes que se fuesen produciendo hasta ajustar su número (46). Esta medida precede a la adoptada posteriormente en las Cortes de Toledo de 1480 , en que para poner fin al crecimiento de regidores, se decidió que los cargos desapareciesen conforme fuesen produciéndose vacantes, por renuncia o fallecimiento de sus titulares (47).

Sus cometidos y atribuciones eran muy amplios, puesto que intervenían con voz y voto en los ayuntamientos.

Ruiz Funes plasma en uno de sus trabajos las atribuciones de los regidores:

1. Elección de oficiales.

2. Administración de las rentas y bienes del común.

3. Vigilancia y supervisión de obras públicas de la ciudad, ayudados por los jurados.

4. Velar por la seguridad jurídica y vital de todos los vecinos sin excepción.

5. Poseían, junto con los alcaldes de la ciudad una facultad de tipo normativo plasmada en forma de peticiones al Rey, bandos ciudadanos, aprobación de ordenanzas municipales, peticiones a Cortes etc.

6. Elevación de propuestas al Rey por incumplimiento real o de sus oficiales de los fueros y privilegios de la ciudad.

(46) A.M.M., Ac. Cap. 1471-72, sesión: Sábado, 20-VI-72.

(47) Cortes de León y Castilla, IV, págs. 164-166. 
7. Junto a los oficiales y jurados los regidores eran los encargados del mantenimiento de la paz, defendiendo los intereses de la ciudad y el mejor servcio real (48).

Abellán Pérez alude igualmente a estas atribuciones de los regidores en su estudio sobre el concejo murciano, destacando su intervención en todos los asuntos públicos de la vida municipal:

* Ordenación de mercados: regidor ejecutor.

* Administración: regidor contador.

* Elección procuradores junto con los jurados.

* Ostentan una llave del arca donde guardaban los pendones.

Como afirma Veas Arteseros (49) este conjunto de facultades ponía en manos de los regidores un dominio efectivo sobre la ciudad, lo que traía consigo el en riquecimiento social del individuo que ejercía el cargo. A estas atribuciones se hace mención en los libros de Actas, así en 1464 acordaron que los regidores que en adelante fuesen procuradores de cortes debían ir acompañados por un hombre encabalgado y ot ro de a pie (50).

Este mismo año se alude a su facultad de ostentar anualmente las llaves de los sellos, precisando que el regidor en quien recayese dicha guarda de las llaves debía llevar durante ese año el pendón del Rey en la procesión del Cuerpo de Dios, por ello le serían pagados de los

(48) Cerdí Ruiz-Funes, J: «Hombres buenos y jurados y regidores en los municipios castellanos de la Baja Edad Mediam, en Actas del I Symposium de Historia de la Administración, Madrid, 1970, pág. 27.

Atribuciones recogidas por Veas Arteseros, Francisco en su artículo sobre regidores: "Dinámica del concejo de Murcia (1420-1440): Los regidores", en Miscelánea Medieval Murciana, vol. IX., Departamento de Historia Medieval, Universidad de Murcia, 1982, págs. 87-117.

(49) Veas Arteseros, F: Ob. cit.

(50) A.M.M., Ac. Cap. 1463-64, sesión: Viernes, 21-XII-64. 
propios del concejo 500 maravedís. En caso de delegar este cometido, únicamente podía hacerlo en otro regidor, bajo pena de perder el salario establecido (51).

En 1472 encontramos referencias a su competencia en las causas criminales, por sorteo se elegían dos regidores y los ju rados que, junto con los alcaldes ordinarios debían actuar en dichas causas, debiendo prestar juramento del buen desempeño de su cargo (52).

Como oficio del ayuntamiento que era, los regidores tenían derecho a percibir un suelo anual. Este ascendía a 1.500 maravedís en período $1462-1474$.

Por acuerdo concejil de 1466 se fija que ni los regidores ni los jurados pudiesen traspasar sus oficios, con ni sin dinero, a ot ras personas debiendo desempeñarlos personalmente y pudiendo designar a alguien en su lugar, únicamente cuando se ausentasen de la ciudad (53).

La duración del cargo a demás del carácter vitalicio que llegó a tener, denota igualmente la continuidad en él de determinadas familias. Esto se conseguía mediante la transmisión en vida por renuncia de su titular. Así en 1465 Juan Vicente, el mozo, pasó a ocupar el lugar de su padre Juan Vicente el viejo, desempeñan do a partir de entonces el regimiento de la ciudad (54). De igual manera, en el año de 1467, compareció ante el concejo Manuel de Arróniz, quien en presencia de Francisco Pérez Beltrán, escribano, presentó e hizo leer una carta del Rey por la que éste le hacía merced del regimiento de la ciudad, por renuncia de su padre Sancho González de Arróniz, el cual había desempeñado dicho oficio hasta ese momento (55).

(51) A.M.M., Ac. Cap. 1463-64, sesión: Sábado, 23-VI-64.

(52) A.M.M., Ac. Cap. 1471-72, sesión: Martes, 9-VI-72.

(53) A.M.M., Ac. Cap. 1465-66, sesión: Sábado, 22-VI-66.

(54) A.M.M., Ac. Cap. 1465-66, sesión: Martes, 2-VII-65.

(55) A.M.M. Ac. Cap. 1466-67, sesión: Sabado, 22-VI-66. 
Según hemos apuntado anteriormente, al hablar de la composición del concejo, llegó a ser normal la escasa concurrencia de los regidores a los ayuntamientos. Aceptaban su obligación de asistir a ellos, pero no siempre la cumplían, ante lo cual el concejo acordó imponer una pena de un real cada vez que se ausentasen (56).

Francisco Veas apunta cómo en ocasiones esta inasistencia a los ayuntamientos era una medida deliberada para retardar algunas resoluciones pendientes a las que no resultaban afectos (57).

\section{Jurados}

Al igual que ocurría con los regidores, los jurados eran oficiales de designación real, una vez elegidos debían prestar juramento de su cargo ante el con cejo con la fórmula tradicional de guardar el servicio del Rey y el bien común de la ciudad, comprometiéndose a denunciar ante el monarca todas las irregularidades que observasen en el desarrollo de la vida concejil. Tras ello estaban obligados a dar fiadores.

Con la reforma llevada a cabo por Juan II en 1424, la duración del cargo se convirtió en vitalicia, transmitiéndose mediante renuncia en vida.

Los jurados participaban en las deliberaciones de los ayuntamientos como portavoces de las distintas colaciones de la ciudad, San Juan, Santa Eulalia, San Lorenzo, Santa María, San Bartolomé, Santa Catalina, San Pedro, San Nicolás, San Antolín, San Miguel y San Andrés, haciendo llegar al concejo los problemas cotidianos, ello justifi-

(56) A.M.M., Ac. Cap. 1470-71, sesión: Martes, 16-X-70.

(57) Veas Arteseros, Francisco: Ob. Cit. 
cará su presencia en las reuniones concejiles, dado que aunque gozaban de voz no tenían derecho a voto. Sus facultades iban desde la general de actuar como vigilantes del bien común, a la ordinaria de empadronar vecinos, recaudar contribuciones y derramas concejiles, así como la parte correspondiente de los servicios extraordinarios. Carecían de remuneración, a menos que desempeñasen algún oficio concejil, no obstante este oficio debía ser apetecible ya que conllevaba el privilegio de la exención del pago de cualquier tipo de impuestos y pechos concejiles, así omo el honor de pertenercer a la minoría dirigente.

En cuanto a su número, a partir de Juan II se fijó en 21 jurados perpetuos, reforma que con ligeras modificaciones persiste hasta el siglo XVI.

En 1466 el concejo delimitó sus competencias, prohibiéndoles ejercer de ejecutores y viceversa (58). Respecto a los ju rados ejecutores siguieron siendo nombrados anualmente, según aparece recogido en las Actas.

Jurados y regidores formaban un bloque, unido por intereses familiares y de clase.

\section{Alcaldes}

El régimen de corregidores conllevaba la supresión inmediata de la competencia judicial de los alcaldes mayores, al menos en teoría, ya que dichos alcaldes actuaban como jueces ordinarios en casos de índole civil y criminal, no teniendo razón de ser en casos de haber corregidores, por ser estos los jueces natos del destrito, aunque por lo ge-

(58) A.M.M, Ac. Cap. 1466-67, sesión: Domingo, 4-X-66. 
neral solían delegar parte de sus atribuciones judiciales en un alcalde o teniente de corregidor nombrado al efecto. De esta forma las únicas prerrogativas que conservaban los alcaldes mayores, además de las puramente honorificas, fueron las de poder asistir a los ayuntamientos con voz y voto, percibiendo por su trabajo un salario.

Murcia contaba con dos alcaldes ordinarios. Estas alcaldías fueron muy codiciadas por la oligarquía urbana como medio de alcanzar prestigio social, poder político y beneficio económico (59).

Tras prometer obediencia al monarca tomaban posesión de su cargo ante el concejo, siéndoles entregadas las varas de la justicia como elemento distintivo del cargo. Los alcaldes estaban obligados a presentar fiadores que les avalasen, debiendo pagar, como apuntamos anteriormente, 375 maravedís al año en concepto de derecho por el desempeño del oficio.

Los libros de actas de estos años presentan constancia anual del nombramiento de estos oficiales, haciendo posible la elaboración de un elenco de ellos.

Aparte de su asistencia a las sesiones del concejo, a partir de 1470 y por decisión del ayuntamiento, se acordó que los alcaldes de la ciudad debían reunirse ellos solos todos los primeros viernes de cada mes, penando su incumplimiento con veinte maravedís (60).

Además de los alcaldes ordinarios, Murcia contó durante estos años con alcaldes encargados de jurisdicciones y funciones especiales.

4.1. Así encont ramos alcaldes entre cristianos y judíos, encargados de resolver los pleitos que pudiesen surgir entre los miembros de ambas comunidades religiosas.

(59) Historia de la Region Murciana, T. IV. Francisco Chacón y ot ros.

(60) A.M.M., Ac. Cap. 1469-70, sesión: Viernes, 1-VI-70. 
Al igual que en el resto de los cargos que venimos analizando, su nombramiento tenía lugar el día 24 de Junio, festividad de San Juan, renovándose anualmente, estando obligados a presentar fiador que los avalase.

4.2. Alcaldes de la Huerta. Estos oficiales, junto con los sobreacequieros de las acequias mayores, eran elegidos anualmente el primer domingo de Cuaresma, con intervención de regidores y de vecinos «herederos de la huerta». En 1469 se resolvió, como ya hemos indiado, que su elección tuviese lugar ocho días antes de la Pascua.

Fue normal comprometerse con ciertas personas para que ocupasen estos cargos, así casi recién inaugurado el año concejil 1463-64, concretamente en el mes de Julio, en ayuntamiento, se hizo público el compromiso de nombrar para el año siguiente a Gonzalo Fernández del Caballo, como uno de los alcaldes de la huerta. A esta decisión se opusieron los jurados según consta en acta (61).

\section{Alguacil mayor}

Oficial encargado de la ejecución de los mandamientos judiciales y del mantenimiento del orden en la villa, empresa que a veces no se conseguía plenamente, lo que obligaba al concejo a recordar a estos oficiales el objetivo de su cometido. En 1471 el Adelantado, por remediar y evitar daños pidió tanto a los alcaldes como al alguacil que con diligencia cumpliesen y ejecutasen la justicia (62).

En 1469 denunciaron ante el Adelantado cómo Fernando de Estúñiga, alguacil mayor y Alfonso de Dávalos, quien por designio del

(61) A.M.M., Ac. Cap. 1463-64, sesión: Sábado, 30-VII-63.

(62) A.M.M, Ac. Cap. 1471-72, sesión: Sába do, 29-VI-71. 
primero desempeñaba el cargo, habian proferido palabras injuriosas contra el regimiento, falta grave, dado que ellos eran representantes del orden, poniendo en entredicho su capacidad para ello. El Señor Adelantado mandó investigar el asunto acaecido, disponiendo que, mientras se resolvía, Alfonso de Dávalos permaneciese retenido en su casa, bajo pena de perder sus bienes si infringía tal orden y que Fernando de Estúñiga fuese llevado preso a la cárcel de la corte (63).

Su toma de posesión se celebraba con arreglo a las mismas formalidades que los restantes cargos locales, tras prestar juramento de su cargo, recibían la vara de la justicia y procedían a la presentación de fiado res.

Dada la amplitud y diversidad de cometidos que se le encomendaban, se hacía necesario contar con auxiliares que le ayudasen en el desempeño de su actuación, surgiendo de esta manera los llamados «alguaciles menores".

Para sustituir al alguacil cuando se ausentaba de la ciudad se nombraban los lugartenientes del alguacil. En 1466, por acuerdo concejil, se ordenó que aquellas personas que hubiesen sido lugartenientes de alguacil no podrían volver a desempeñar un cargo público hasta pasados siete años (64).

Los alguaciles mayores debieron ausentarse con frecuencia de la ciudad, lo que explica el acuerdo tomado por el concejo en 1467, resultando que el alguacil no podría ausentarse de Murcia por un tiempo superior a un mes (65).

Este mismo año, ante la denuncia de frecuentes robos y delitos cometidos en las diversas colaciones, con ánimo de zanjarlos ordena-

(63) A.M.M., Ac. Cap. 1468-69, sesion: Martes, 30-V-69.

(64) A.M.M, Ac. Cap. 1465-66, sesión: Sábado, 22-VI-66, reiterado el acuerdo en Lunes, 23-VI-66.

(65) A.M.M., Ac. Cap. 1466-67, sesión: Martes 23-VI-67. 
ron que fueran puestos alguaciles menores en cada una de dichas colaciones, encargándose de su nombramiento los jurados y vecinos de cada una de ellas, resultando elegidas las siguientes personas:

* San Juan del Arrabal Bartolomé de Bechi.

* Santa Olalla: Alfonso de Olmedo.

* San Lorenzo: Diego del Pollo.

* Santa María: Alfonso Martín de Albacete.

* San Bartolomé: Alfonso González, armero.

* Santa Catalina: Juan Rodríguez, barbero.

* San Pedro: Juan Artero.

* San Nicolás: Juan Martínez, carnicero.

* San Antolín: Salvador de Belbis, barbero.

* San Miguet Martín Pulleda.

Estos nombramientos, realizados en el mes de Enero, tendrían validez hasta el día de San Juan de Junio, dichos alguaciles prestaron juramento de prestar su oficio ubien y lealmente» (66).

Con el mismo propósito en 1470 ordenaron a los jurados de la ciudad que nombrasen, cada uno en su colación: «una buena persona para ser alguacilm, por la cantidad de robos que se hacían en la ciudad (67).

En Acta Capitular de 1464 se hace referencia al sueldo del alguacil, 1.500 maravedís (68).

Para evitar que estos oficiales se excedieran en el desempeño de su cometido, llegando a provocar abusos de poder, su actuación era supervisada, siéndoles aplicada la justicia en los casos necesarios. Puede servir de ejemplo un caso ocurrido en 1472 , cuando era alguacil

(66) A.M.M., Ac. Cap. 1466-67, sesión: Jueves, 8-I-67 y Martes, 13-I-67.

(67) A.M.M., Ac. Cap. 1469-70, sesión: Martes, 9-I-70.

(68) A.M.M., Ac. Cap. 1462-63, sesión: Martes, 4-I-63. 
Alfonso Hurtado, quien sin mandamiento del juez encarceló en su casa a un vecino de la ciudad por cierto delito cometido, reteniéndole hasta que le fue entregada una fianza de 3.000 maravedís, por todo ello y según la ley real vigente entonces, se le privó del oficio de alguacil durante ese año (69).

\section{Procurador del concejo.}

Además de su misión como representante del concejo en la corte o ante los tribunales, el procurador era antes que nada el portavoz de los derechos del concejo, velando por el bien general y denunciando cualquier abuso o irregularidad que se cometiese atentando contra el derecho de la ciudad (70).

El cargo lo desempeñaba un regidor qer era elegido anualmente el día de San Juan, tenía como obligación asistir a todas las reuniones que se celebrasen. Se nombró, además de estos procuradores de cortes, un número variable de representantes de la ciudad, conocidos igualmente como procuradores, teniendo como misión el representar al concejo en sus diferentes campos de actuación.

\section{Contadores del concejo.}

Los contadores del concejo eran los encargados de supervisar la Hacienda municipal, arrendamiento de las rentas de propios de la ciudad, revisar las cuentas del mayordomo y, en general, de todas las personas que estuviesen encargadas de cobrar los derechos concejiles y comprobar que el dinero de la ciudad se gastaba de manera correcta.

(69) A.M.M, Ac. Cap. 1472-73, sesión: Martes, 3-XI-72.

(70) González Jiménez, Manuel: El concejo de Carmona a fines de la edad media (1464-1523), Sevilla, 1973. 
Anualmente el día de San Juan, como era habitual, se elegía un regidor $y$ un jurado para que ostentase durante un año el oficio de contadores. A ellos correspondía la decisión de poner fieles cogedores que eran los encargados de cobrar los impuestos que se arrendaban.

\section{Mayordomo del conajo.}

El mayordomo, que se elegía el citado día de San Juan de Junio, era una figura esencial en la Hacienda municipal. La competencia de éste era la de recaudador general, centralizando la mayoría de los ingresos, arrendaba las rentas del concejo y efectuaba los pagos de los gastos ordina rios por propia decisión cuando tales gastos no excedían de una ciert a cantidad de maravedís y, por orden del concejo, cuando los gastos eran superiores.

Requisito imprescindible para ser mayordomo era el que este no fuera hijosdalgo, aunque por regla general, pertenecía a las familias más importantes.

El salario estipualdo para el mismo era de 1.500 maravedís, participando además en una serie de derechos y multas, reservándoseles la tercera parte de las multas extraordinarias, si la imposición no era de la competencia de los alcaldes o del alguacil (71).

\section{Veedores del concejo.}

Para este cargo se designaba un regidor que debra examinar los paños y telas que habra en la ciudad, antes de que se vendiesen garantizando así su legitimidad, como en casos anteriores también se elegían el día de San Juan de Junio.

(71) Para el estudio de la figura del Mayordomo y sus consecuencias, nos ha sido de gran utilidad la obra de Denis Menjot: Fiscalidad y sociedad. Los murcianos y el impuesto en la Baja Edad Media, Academia Alfonso X el Sabio, Murcia, 1986. 


\section{Almotacén.}

Inspecionaba y controlaba la actividad económica, desde tiempos de Alfonso $\mathrm{X}$ el mercado y las transacciones que se realizaban en el mismo fueron competencia de un almotacén.

Elegido el 24 de Junio y tras presentar a sus fiadores entrega los 375 maravedís estipulados que, por regla general se les devolvía al interesado cuando terminaba el año concejil, siempre que el Rey no ordenase lo contrario (72).

Entre sus atribuciones sobresalen:

* Comprobar que los pesos y medidas utilizados en la venta al público resultasen fieles.

* Velar por el cumplimiento del horario de venta y por el estado de los alimentos objeto de la misma.

Para desempeñar sus funciones estaba auxiliado por almotacenes menores que eran nombrados tras el consentimiento de los jurados.

La remueración del mismo se efectuaba mediante los derechos cobrados en todas sus intervenciones según arancel, percibiendo la mitad de esa cantidad, el resto era para las arcas del concejo.

\section{Escribanos.}

En tiempos de Juan II se reconoce a Murcia el derecho a nombrar dieciocho escribanos de número.

El cometido de los mismos era el de asentar los acuerdos a que llegase el concejo y en general certificar la autenticidad de hechos y circunstancias.

(72) En 1464 las Actas recogen la noticia de cómo el concejo devolvió al almotacén del año anterior, los 375 maravedís que tuvo que entregar como fianza de su oficio al concejo. 
11.1. Escribanía del concejo.

Por su naturaleza era la más importante de las existentes en la ciudad.

Durante la mayor parte del período que estudiamos fue escribano mayor del concejo Francisco Pérez Beltrán, sus obligaciones eran:

* Usar bien y lealmente de su oficio.

* Asentar en el libro de Actas todo lo que ocurriese en las reuniones del concejo.

* Guardar secreto de lo tratado en los cabildos.

11.2. Escribanos públicos de número.

En Murcia había dieciocho escribanías públicas siendo requisito previo, para acceder a este cargo, superar un examen en que el candidato demostraba su habilidad y suficiencia, las condiciones que se les exigía, eran varias, entre las que destacan:

* En primer lugar ser oriundo de la ciudad.

* Haber cumplido dieciocho años.

Entre sus obligaciones cit aremos:

* El consabido usar «bien y lealmente de su oficio».

* Guardar secreto de testamentos y contratos.

* No cobrar precios abusivos por su trabajo, ajustándose a los cotos establecidos por el concejo (73).

(73) Piqueras García, M.a Belén: "Cotos de los escribanos de Murcia en 1472", en Homenaje al Prof. Juan Torres Fontes, vol. II. Univ. de Murcia, Academia Alfonso X el Sabio, Murcia 1987, pág. 1303-1313. 
En 1464 el concejo prohibió a los escribanos que en adelante se arrendasen los escribanfas de los jugados de los alcaldes y alguacil durante más de un año, después del cual deberían estar sin arrendarlas nuevamente hasta transcurridos cuatro años, debiendo comenzar el arrendamiento el día de Navidad (74). Al mes siguiente de la expedición de esta orden algunos escribanos elevaron al concejo su petición de que fuese revocada (75). No aparece ninguna otra alusión al respecto.

El resto de las escribanías no podran -al menos en teoría- ser arrendadas ni tampoco poner en ellas sustitutos, excepto si la causa era legítima y aún en este caso debran contar con la licencia de los alcaldes.

En los libros de Actas encontramos algunas renuncias de escribanos, siendo la causa más corriente alegada para ello, tener una edad avanzada y estar imposibilitado para poder desempeñar el oficio adecuadamente (76).

En 1474 se ordenó que los escribanos de la ciudad presentasen sus títulos con la finalidad de ver si todos los que desempeñaban el oficio lo hacían debidamente. En sesión del concejo del mes de junio de ese mismo año aparecen mencionados los escribanos que, acatando la orden dada por el concejo, se personaron para presentar sus títulos:

$$
\text { * Francisco Pérez Beltrán. }
$$

(74) AMM, Ac. Cap. 1464-65, sesión: Martes, 27-Xl-64.

(75) A.M.M, Ac. Cap. 1646-65, sesiones Sábado, 1-XII-64 y Sábado, 15-XII-64.

Juan ALfonso Escarramand, Francisco Ruiz y Alfonso Pérez, escribanos de las escribanias del juzgado de los alcaldes ordina rios, fueron los que presentaron tal petición.

(76) A.M.M., Ac. Cap. 1464-65, sesión: Martes, 10-VII-64.

Renuncia de Juan ..., por ser muy viejo, tenia 94 años y además estaba ciego, designaron en su lugar a Diego Riquelme.

Ac. Cap. 1468-69, sesión: Sábado 15-IV-69. Renuncia de Alfonso Pérez de Monzón, como escribano público, por ser muy viejo, proponiendo para que lo sustituyera, a Pedro López, fue aceptada su propuesta. 


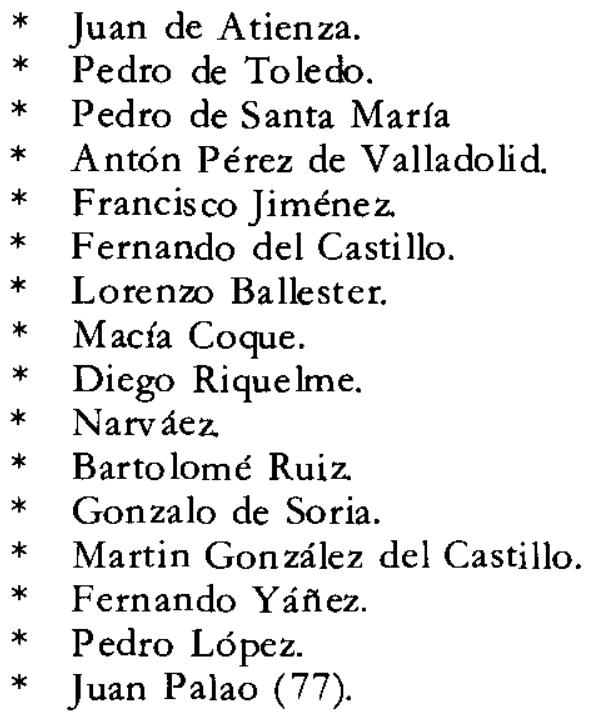

12. Oficiales de la buerta.

Nombrados anualmente el primer domingo de Cuaresma regían, juzgaban y administraban todos los asuntos de la huerta.

Entre estos oficiales sobresalen:

* Alcaldes de la huerta, ya citados en el apartado referente a los alcaldes.

* Sobrecequieros de ambas márgenes del río.

* Escribanos de alcaldes y sobrecequieros.

(77) A.M.M, Ac. Cap. 1474-75, sesión: Martes, 28-VI-74. 


\section{Otros cargos.}

Además de los oficios concejiles reseñados en las actas aparecen reflejados ot ros cargos de funcionarios.

* Pregoneros del concejo, ostentando dicho oficio durante estos años Juan de Cieza, teniendo la misión de informar, recorriendo plazas y lugares céntricos hacía llegar a la población todo tipo de acuerdos y noticias (78).

Para enviar mensajes fuera de la ciudad se utilizaban andadores y mensajeros.

* Portero del concejo, Francisco de Sevilla durante este período.

En las actas de 1465 queda reflejado el pago de 300 maravedís para ayudar a pagar el alquiler de la vivienda del mismo (79). La misión del portero era la de comunicar la celebración de reuniones a los miembros del concejo, llevando de un lado a ot ro específicos mandatos y tener dispuesta la sala donde se celebraban las reuniones.

* Verdugo del concejo, encargado de las ejecuciones físicas de los reos, cobrando un salario. No abundaban en la ciudad, por lo que en 1463 el concejo se ve obligado a dar una orden por la que se faculta al alguacil para elegir vergudo entre los moros libres, bajo pena si se negasen a ello de 600 maravedís $(80)$.

En 1464 y seguramente con objeto de hacer más apetecible el cargo, mandaron pregonar que la persona que quisiese ser verdugo de la ciudad, tendría un salario de 2.000 maravedís (81).

(78) La Plaza de Santa Catalina era el marco principal de estos pregones.

(79) A.M.M., Ac. Cap. 1465-66, sesión: Sábado, 20-VII-65.

(80) A.M.M, Ac. Cap. 1463-64, sesión: Sábado, 16-VII-63.

(81) A.M.M, Ac. Cap. 1464-65, sesión: Jueves, 15-XI-64. 
Este salario permanecería invariable hasta 1472 , año en que el verdugo de la ciudad protestó por el escaso salario que percibía, dado el cometido de su trabajo, ante ello el concejo ordena al mayordomo que se le pagase los 2.000 maravedís y los alcaldes le darían 25 maravedís mensuales cada uno además de los 500 maravedís que le daría el Adelantado al Año.

Este sala rio sería incrementado en 150 maravedís al mes (82).

* Guardas. El motivo de su aparición es la constante inestabilidad político militar, por ser Murcia un reino de fronteras.

Dentro del capítulo de funcionarios se encontraban también los letrados, médicos, relojero, maest ro de gramática, etc.

(82) A.M.M, Ac. Cap. 1472-73, sesión: Sábado, 22-VIII-72. 